\title{
ERP Crisis Management Through Leadership Communication
}

Duane E. Ramirez, University of the Incarnate Word, USA

\begin{abstract}
This article details enterprise resource planning (ERP) crisis management through leadership communication. It begins with a review of alternative crisis management solutions. The author presents leadership communication as a solution to ERP crisis management. A discussion on communication techniques and strategies follows. Finally, recommendations for future research and conclusion complete the article.
\end{abstract}

Keywords: Enterprise Resource Planning, ERP, Leadership Communication, Crisis, Crisis Management, Technology Implementations

\section{INTRODUCTION}

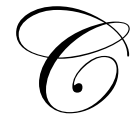

onsider a multinational corporation, operating in several countries, contending with different languages, laws, customs, and individuals. These needs demand different operations. Now consider combing resources, technology, and processes, know as enterprise resource planning (ERP). ERP creates crisis, an impending decisive change with possible undesirable outcomes due to situations reaching a critical phase (Webster, 2009). Crisis within ERPs are real and progressive, requiring management to negotiation. Leadership communication provides positive results, expanding knowledge, confidence, and support.

Short and long-term effects are numerous. ERP implementations elevate stress on resources. Management requires flexibility and focus. Successful ERP implementations accommodate growth and align operations to market success. ERP's goal is streamlined processes via best business practices and technology utilization. More than automation, ERPs redefine organizations. Crisis management is critical to success.

This article discusses ERP crisis management through leadership communication. It reviews alternative crisis management solutions, presents leadership communication as a solution for success, provides a discussion on techniques and strategies of leadership communication, and recommends future research.

\section{ALTERNATIVE SOLUTIONS}

Crisis management maintains image and determines position and cause (Coombs, 1995). Solution review is challenging. From industry, methodology, and crisis uniqueness, organizations consider experiences exclusive. Most ERPs utilize crisis management plans. These focus on three areas including challenging preparations, determining organizational behavior (to include personnel), and communication to stakeholders (Sturges, 1994). Communication receives little attention, allocated to preparation. The result is poor communication during and post crisis (Sturges, 1994). Once a crisis begins, it is too late to formulate a plan (Barnett, 2007). This includes technology utilization, which Barnett (2007) suggests low-tech backups. In ERPs, this may not be an option.

Holland and Gil (2006) found sixty-nine percent of organizations implemented a crisis plan in response to events affecting operations. Of this, only forty-seven percent fully implemented their plans, while the remaining fifty-three percent implemented elements of their plans. On organizations with no crisis plan, only forty-six percent began to develop one. Forty-two percent take no action (Holland \& Gill, 2006). Fifty-four percent of respondents stated senior management does not consider crisis plans a priority. For ERP implementations, this is unacceptable. 
Another solution consists of crisis teams. Team goals focus on bringing ERP implementations back to normalcy. Crisis teams comprises of individuals from public relations, chief of staff, administration, and legal, providing objective and analytical advice (McCartney, 2004). They seek to avoid groupthink, "thought characterized by self-deception, forced manufacture of consent, and conformity to group values, and ethics" (Webster, 2009). Additional problems occur when team members balance multiple responsibilities and give participation a lower priority.

ERP's posture effects perception, internally and externally. This includes positive and negative views, and neutral history, where the public knows nothing about organization until the crisis is at hand (Coombs, 1995). Regardless of the plan created or resource allocation, key strategies to successful crisis management come from communication.

\section{Signal International}

Signal International is an example of an ERP troubled by bad communication. Signal International, a multinational corporation based in Australia, has offices in Sydney, Detroit, and Zurich, smaller branches worldwide, and production facilities in India and China (ERPWire, 2009). The ERP set to consolidate all operations. E-Systems and Tuukku were the consultants and Global Lease was the software utilized.

Problems begin in the implementation process (ERPWire, 2009). Signal did not have common practices organization wide, including several acquired companies, each with its own operating standards. Communication did not exist between locations causing individual offices misuse the ERP. The result was an ineffective ERP with miscommunications effecting technical and functional operations.

Lack of leadership communications resulted in problems with software selection, training, and schedules (ERPWire, 2009). The ERP created more problems that it set to solve. The responsibility is management and its ability to contain crisis as they arise.

\section{LEADERSHIP COMMUNICATION}

For many, leadership is behavioral and a position. This article focuses on leadership in terms of managerial positions. Management consists of allocating resources and dictating ERP actions. The communication presented has different effects in an ERP implementation. For crisis management, sound leadership takes a proactive stance. Leadership communication focuses transferring the organization to normal operations (King, 2007). Relationships between leaders, employees, stakeholders, and external persons directly affect these activities. King (2007) notes how a leader's attitude towards organizational personnel affects success. A leader carries their history of positives and negatives into a crisis. Day to day leadership differs greatly from crisis leadership. Leaders contend with an assortment of challenges during crises. Time, scope, and budget all require attention. In a crisis, factors such as information gathering, preparation, and experience play a substantial part in the actions taken by leadership (Schoenberg, 2005).

\section{DISCUSSION}

Communication dictates strategy, a foundation to ERP implementations. This provides information to proper stakeholders at the right time. The information should be correct and focused. At its core, leadership communication incorporates knowledge transfer. Coombs (1995) suggests several communication strategies, each providing different results. Nonexistence strategy denies crises and attacks reporters, sometime using intimidation and organizational power to discredit sources of such claims. Coombs (1995) describes distance strategies as excuses to minimize responsibility and provide justification on actions taken. Ingratiation seeks public approval for activities and outcomes from the crisis. Finally, mortification seeks forgiveness for organizations, activities, and the crisis as a whole.

Communication also includes what items not spoken. Phelps (2007) describes seven deadly sins leaders communicate, including hypocrisy, deception, insensitivity, abuse of power, waste, incompetence, and cowardice. 
Leaders should decimate each, despite obvious political and controversial aspects. Consider deception in communication. What effects are there if leadership lies at critical moments in a crisis? At the least, the crisis extends; at worst, a new crisis emerges. Verbal and nonverbal communication is crucial to ERP implementations. Good leaders are visible, continue communications, and maintain focus. Communication display control, beginning with identifying leaders. Alexander Haig's declaration of control following the attempt on Ronald Regan's life is an example of miscommunication and demonstrates Wilson's (2004) belief that communication starts with internal staff before presented externally. Haig's communication displays control, another point by Wilson, yet miscommunication on true leadership hierarchy muddled the crisis and created another one. Haig could not acknowledge the crisis' end, a factor in leadership communication (Wilson, 2004).

Coombs (1995) notes how leadership communications shape public perception and opinions. Many leaders do not plan for this. Leaders operating in a vacuum, connected only by crisis, present alienating communication that does not consider the emotions of others (Friedman, 2009). The communication lacks effectiveness and avoids controversial topics with leaders talking around critical topics. Communication should be consistent and correct. Friendlier language versus straightforward talk confuses communication and sometimes makes the situation and crisis worse (Kwan, 2009).

Struges (1994) suggest that good communication is malleable in formative stages of the crisis. It immediately manages rumors as only over time are these formative opinions changed (Sturges, 1994). In a crisis, opinions formulate immediately and leadership communication creates calm and avoid miscommunications. Malski (2008) notes common leadership answers include "no" because "no" changes to "yes" more than "yes" changes to "no." This may be stylistic as connections between crisis and leader are elaborate cause/effect relationships. Schoenberg (2005) suggests that in studying leadership traits, situations determine leaders. With crisis changes come new techniques, tools, and communications. Communications for natural disasters differ from product recalls. Poor communication places personnel in danger while permanently damaging organizations and leaders (Carr, 2009). Carr (2009) mentions how an organization's reputation recovery relates to leadership's crisis management. Stakeholders reflect on the communication. Blame is an excellent example. It formulates early and continues during the crisis, existing in post crisis environment.

Leadership must acknowledge their actions since they are focal points during crisis. This comes from communication strategies establishing ERP credibility. Actions speak louder than words and not all communication is verbal. Physical presence speaks volumes towards commitment. Successful communication contains transparency, disclosing all available information as quickly as possible (Smith, 2009). Transparency details safety, timelines, and remedies. If respondents do not hear this from leadership, outside parties deliver it (Smith, 2009). An external version is rarely synonymous with leadership's vision, and generally blurs the overall message.

\section{FUTURE RESEARCH}

Diverse viewpoints exist in the literature. Gaps arise with articles inspired by the events of their day. Examples include Columbine High School and Virginia Polytechnic Institute and State University shooting, hurricanes Katrina and Rita, the terrorist attacks of September 11, 2001, and the financial crisis of 2008. Given patterns, expect articles on the swine flu outbreak of 2009. Yet this highlights the need for research. Representation of communication is minimal, usually regulated to a section. Research on ERP crisis management through communication is smaller.

This topic needs additional research. Consider ERP effects on business and the changes it creates. Participants view these changes as crisis. Research could prepare leadership with ERP specific management techniques. The belief is each ERP is unique and shared experiences are nonexistent. Research could connect industries that would normally not share ideas. Removing vacuums and dismantling silos Additional research to provide foundations for ERP communications managing crisis would benefit this. Lessons learned focused on leadership, are topics for further research. 


\section{CONCLUSION}

Communication is the foundation to sound leadership. ERP are unique from typical business operations, requiring specific management that is both flexible and transparent. During a crisis, leadership is at focus due to management of critical assets. While management, vision, and style are vital, many agree the test of leadership is crisis. With the limited time of ERP implementations, there is no room for error. Silence in crisis leads to ruin, while open communication is the path to success.

This article presented ERP crisis management through leadership communication. The alternative solutions are sound but require communication from ERP leaders to succeed. Leadership communication should be the initial solution for ERP crisis management. The number of techniques and strategies need further research to create tools useful in real world ERP implementations. Businesses contemplating ERPs need leadership willing to handle the changes and crisis that arise. Only leadership with transparent, honest, and focused communication will take ERPs out of crisis and towards future success.

\section{AUTHOR INFORMATION}

Duane E. Ramirez is a PhD student at the University of the Incarnate Word. His major is Organizational Leadership. He has a Master of Arts in Computer Resource \& Information Management as well as a Master of Business Administration from Webster University. In addition to his studies, his professional work includes training, change management, and technology utilizations. Past positions include analyst, consultant, and project/program management.

\section{REFERENCES}

1. Barnett, N. (2007). The PR Response to Virginia Tech and Beyond. Communication World, 24(4), 14-15.

2. Carr, N. (2009). Times Have Changed. American School Board Journal, 196(4), 57-58.

3. Crisis. (2009). In Merriam-Webster Online Dictionary. Retrieved March 23, 2009, from http://www.merriam-webster.com/dictionary/crisis.

4. Coombs, T. W. (1995). Choosing the Right Words: The Development of Guidelines for the Selection of the "Appropriate" Crisis-Response Strategies. Management Communication Quarterly, 8(4), 447.

5. ERPWire. (2009). ERP failures and manual actions in Signal International. Retrieved July 16, 2009 from http://www.erpwire.com/erp-articles/erp-failures-and-manual-actions.htm\#.

6. $\quad$ Friedman, K. (2009). Be Prepared For Any Crisis. Communication World, 26(2), 14.

7. Groupthink. (2009) In Merriam-Webster Online Dictionary. Retrieved Monday, June 29, 2009, from http://www.merriam-webster.com/dictionary/groupthink.

8. Holland, R. \& Gill, K. (2006). Ready For Disaster? Communication World, 23(2), 20-24.

9. King, G. (2007). Narcissism and Effective Crisis Management: A Review of Potential Problems and Pitfalls. Journal of Contingencies \& Crisis Management, 15.4, 183-193.

10. Kwan, F. (2009, January). Communicating Bad Budget News. Leadership, 38(3), 14-16.

11. Malski, J. (2008). Tough Times Require Real Leadership. Westchester County Business Journal, 47(49), 16.

12. McCartney, M. (2004, October). Preparing for the Unthinkable. State Legislatures, 30(9), 32-33.

13. Phelps, R. W. (2007). Planning for the Worst. Engineering \& Mining Journal, November, 77.

14. Schoenberg, A. (2005). Do Crisis Plans Matter? A New Perspective on Leading during a Crisis. Public Relations Quarterly, 50(1), 2-6.

15. Sturges, D. (1994). Communicating Through a Crisis: A Strategy for Organizational Survival. Management Communication Quarterly, 7(3), 297.

16. Smith, L. (2009). Volatile Times Demand Persistent Messages. Of Counsel, Volume 28 \#1.

17. Wilson, J. (2004, June 21). Now The Disaster's Happened, What Am I Supposed To Do? Accounting Today, 18 (11), 24-25. 